\title{
Novel composite organic-inorganic semiconductor sensors for the quantitative detection of target organic vapours ${ }^{\dagger}$
}

\author{
Benjamin P. J. de Lacy Costello, Phillip Evans, Richard J. Ewen, Colin L. Honeybourne and Norman M. Ratcliffe* \\ Faculty of Applied Sciences, University of the West of England, Coldharbour Lane, Frenchay, Bristol, UK BS16 1QY
}

Composites of tin dioxide (an n-type semiconductor) and derivatives of the conducting polymer polypyrrole (a p-type semiconductor) gave reversible changes in electrical resistance at room temperature when exposed to a range of organic vapours. The optimum amount of polymer giving highest sensitivity was found by experiment to be $2.5 \%$ by mass for the polypyrrole chloride-tin dioxide composite. Composites containing $2.5 \%$ polymer by mass, but differing in polymer derivative, were fabricated and exposed to low concentrations of ethanol, methanol, acetone, methyl acetate and ethyl acetate. All were found to give significant and reversible decreases in electrical resistance. Direct comparison with sensors constructed solely of tin dioxide or polypyrrole at room temperature showed the composites to be more sensitive. The gas sensitivity of the composite materials depended on the type of polymer derivative incorporated and the dopant anion associated with the polymer. The composites were simple to fabricate and gave differing response profiles to a range of organic vapours.

Organic semiconductors, particularly polypyrrole and its derivatives, have been reported to change their conductivities when exposed to a variety of organic and inorganic vapours. ${ }^{1}$ Recently, polypyrroles with different anions and/or substituents have been incorporated into sensor arrays for artificial nose applications. $^{2}$

Inorganic semiconductors such as tin dioxide, either undoped $^{3}$ or doped ${ }^{4}$ with catalytic metals, have been extensively reported to act as chemical sensors when operated at elevated temperatures, ${ }^{5}$ typically $350^{\circ} \mathrm{C}$.

There are numerous examples of applications of inorganic semiconducting mixtures, e.g. as catalysts and promoters, and in electronic devices (for instance, the electroluminescence exhibited by zinc sulfide and copper ${ }^{6}$ ). In contrast, there are few reports describing the applications of organic semiconducting mixtures. ${ }^{7,8}$

It should be observed that films of organic semiconductors layered with inorganic semiconductor films are currently receiving some attention. For instance, poly ( $p$-phenylene vinylene) has been found to emit light when sandwiched between materials having high (e.g. indium oxide) and low (e.g. alu minium) work functions. ${ }^{9}$ Polypyrrole films on n-type cadmium sulfide (prepared by electrochemical polymerisation of pyrrole on the cadmium sulfide) have markedly improved the stability of cadmium sulfide against photocorrosion, while permitting a light-assisted water cleavage reaction. ${ }^{10}$ Films of inorganic and organic semiconductors have also been shown to possess diode characteristics ${ }^{11}$ and photovoltaic properties at very low efficiencies. ${ }^{12}$ However, there have been no reports of the use of composites of organic and inorganic semiconductors for vapour sensing of organic compounds.

Reported work ${ }^{13}$ on the analysis of soft rot infections (caused by the bacterium Erwinia carotovora) of Russet Burbank cultivar and Kennebec cultivar potato tubers by GC-MS cites an increase in the concentration of organic vapours above the infected tubers. The volatiles emitted in the highest concentrations were ethanol, acetone and butan-2-one. Additional volatiles detected in the headspace of the diseased tubers included acetaldehyde, methyl acetate, ethyl acetate, propanethiol, hydrogen sulfide, dimethyl disulfide, $n$-propanol and isobutyl alcohol.

Current methods for the detection of soft rot in stored

$\dagger$ Presented at the Second International Conference on Materials Chemistry, MC ${ }^{2}$, University of Kent at Canterbury, 17-21 July 1995. potato tubers are expensive and bulky, as in the case of GC-MS, or largely ineffective, as in the case of thermographic monitoring. A system is required which is inexpensive whilst being sensitive to low levels (typically $<10 \mathrm{ppm}$ ) of the vapours. A device of this type would enable early remedial action to be taken, thus reducing financial losses.

The requirements for useful gas sensing devices in a variety of applications are high sensitivity, low cost and portability. Whilst devices based on heated inorganic semiconductors are sensitive to a variety of organic species at low levels, including ethanol, ${ }^{4}$ methanol,,${ }^{14}$ ethyl acetate ${ }^{15}$ and acetone, ${ }^{16}$ the need for elevated temperatures for operation increases the cost of the device and limits the portability. Multi-sensor arrays based on electropolymerised conducting polymers have found a wide variety of applications, especially in the assessment of food ${ }^{17}$ and beverage ${ }^{2}$ quality. Devices of this type, whilst operating at room temperature, are expensive to produce and require complex signal processing. There is scope for the development of new materials displaying different response profiles to those currently available. We have assessed the potential of composites of p-type polypyrrole derivatives and n-type tin dioxide as possible sensors for detecting key analytes of value for the detection of soft rot in stored potato tubers.

\section{Experimental}

Tin(IV) oxide powder ( $99.9999 \%$ purity) was obtained from Janssen Chimica (Geel, Belgium). Pyrrole ( $98 \%$ purity) and $N$-methyl pyrrole ( $99 \%$ purity) were obtained from the Aldrich Chemical Company (Gillingham, Dorset, UK). The tin dioxide was used as received. Pyrrole and $N$-methyl pyrrole were distilled prior to use and stored over $4 \AA$ molecular sieves at $4{ }^{\circ} \mathrm{C}$. Polymerisation of pyrrole and $N$-methyl pyrrole was based upon standard methodologies. ${ }^{18}$

\section{Preparation of polypyrrole chloride (PPCl)}

Copper(II) chloride (1.6 g, $\left.11.9 \mathrm{mmol} \mathrm{dm} \mathrm{dm}^{-3}\right)$ was dissolved in acetonitrile $(35 \mathrm{ml})$. Pyrrole $\left(0.19 \mathrm{~g}, 0.2 \mathrm{ml}, 2.9 \mathrm{mmol} \mathrm{dm}^{-3}\right)$ was added rapidly and the mixture was stirred for $3 \mathrm{~h}$. The black polymer produced was then filtered and washed with acetonitrile $(300 \mathrm{ml})$ before drying in vacuo $\left(0.95 \mathrm{~mm} \mathrm{Hg}, 72^{\circ} \mathrm{C}\right.$, $2 \mathrm{~h}$ ). Yield: $0.14 \mathrm{~g}$ [ $63.6 \%$ based on a $3: 1$ monomer: dopant ratio (see Fig. 1)]. Elemental analysis: $\mathrm{C}, 50.70 ; \mathrm{H}, 2.72$; $\mathrm{N}, 14.76 ; \mathrm{Cl}, 20.11$; ash, $0.37 \%$. 


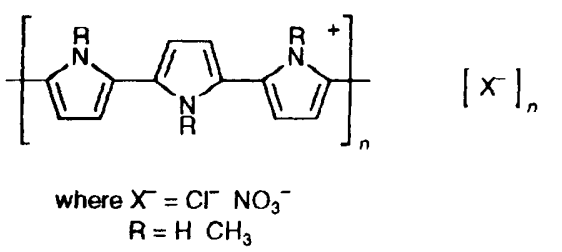

Fig. 1 Idealised polymer structure based on a 31 monomer dopant anıon ratio

\section{Preparation of polypyrrole nitrate $\left(\mathrm{PPNO}_{3}\right)$}

Iron(III) nitrate nonahydrate $\left(454 \mathrm{~g}, 112 \mathrm{mmol} \mathrm{dm}^{-3}\right)$ was dissolved in water $(33 \mathrm{ml})$ Pyrrole $(019 \mathrm{~g}, 02 \mathrm{ml}, 29 \mathrm{mmol}$ $\mathrm{dm}^{-3}$ ) was rapidly added and stırred for $90 \mathrm{~min}$ The polymer was then filtered off and washed with distilled water $(260 \mathrm{ml})$ before drying in vacuo $\left(095 \mathrm{mmHg}, 72^{\circ} \mathrm{C}, 2 \mathrm{~h}\right)$ Yield $021 \mathrm{~g}$ (858\% of the theoretical based on a 31 monomer dopant ratio) Elemental analysis $\mathrm{C}, 5403, \mathrm{H}, 287, \mathrm{~N}, 1819$, ash, $016 \%$

\section{Preparation of poly- $N$-methyl pyrrole chloride (PNMPCI)}

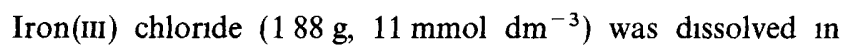
water $(385 \mathrm{ml}) \mathrm{N}$-Methyl pyrrole $(023 \mathrm{~g}, 025 \mathrm{ml}, 29 \mathrm{mmol}$ $\mathrm{dm}^{-3}$ ) was dispersed in water $(15 \mathrm{ml})$ and added rapidly to the iron(III) chloride solution with vigorous stirning, which was maintained for $3 \mathrm{~h}$, prior to filtration The polymer was then washed with water $(320 \mathrm{ml})$ and dried in vacuo $(095 \mathrm{mmHg}$, $72{ }^{\circ} \mathrm{C}, 2 \mathrm{~h}$ ) Yield $008 \mathrm{~g}(30 \%$ of the theoretical based on a 31 monomer dopant ratio) Elemental analysis C, 5924 , H, $397, \mathrm{~N}, 1367, \mathrm{Cl}, 1164$, ash, $621 \%$

\section{Preparation of poly- $\mathrm{N}$-methyl pyrrole nitrate $\left(\mathrm{PNMPNO}_{3}\right)$}

The preparation was the same as for PNMPCl, with iron(III) nitrate nonahydrate $(444 \mathrm{~g}, 0011 \mathrm{~mol})$ used as the oxidant replacing iron(III) chloride Yield $014 \mathrm{~g}(50 \%$ of the theoretical based on a 31 monomer dopant ratio) Elemental analysis C, $6101, \mathrm{H}, 387, \mathrm{~N}, 1550$, ash, $047 \%$

Each polymer was prepared twice (batch 1 and batch 2 polymers) using the methods described, and elemental analysis was carried out on each polymer to ascertain the reproducibility of the syntheses The results displayed in Tables 1 and 2 are for composites comprising batch 1 polymers

\section{Scanning electron microscopy study of materials incorporated into the composites}

SEM images of the polymers showed that the particle size distribution was in the range $10-60 \mu \mathrm{m}$ The micrographs of the polypyrrole further showed that the large particles were formed of agglomerated polydispersed spheres SEM images of the tin dioxide showed the particle size distribution to be in the range $10-30 \mu \mathrm{m}$

\section{Fabrication of substrates for gas sensor testing}

Interdigitated electrodes, possessing three pairs of interpenetrating bars with an electrode gap of $05 \mathrm{~mm}$, were prepared on alumina substrates The design was such that four separate electrodes with a common voltage connection and separate measurement connections fitted onto one alumina square The alumina substrates were cleaned in deionised water prior to sputter coating with gold (Emscope gold sputterer coating current $15 \mathrm{~mA}$ for $3 \mathrm{~min}$ ) The electrode pattern was then created using photolithographic techniques
Table 1 Relative responses of composte sensors with dieu, Article Qnline ages of $\mathrm{PPCl}$ incorporated in their structure when exposed to $100 \mathrm{ppm}$ of ethanol vapour

\begin{tabular}{cc}
\hline $\begin{array}{c}\text { polymer (mass\%) } \\
\text { in the composite }\end{array}$ & $\begin{array}{c}\text { relative response } \\
\text { to ethanol }\end{array}$ \\
\hline 0 & 04 \\
068 & 081 \\
125 & 098 \\
25 & 1 \\
5 & 048 \\
10 & 034 \\
25 & 016 \\
50 & 0 \\
75 & -009 \\
100 & -008 \\
\hline
\end{tabular}

\section{Production and optimisation of composite gas sensitive materials}

Composite materials were produced by grınding various proportions of polypyrrole chloride with tin dioxide in an aqueous slurry Composites containing 0675, $125,25,5,10,25,50$ and $75 \% \mathrm{PPCl}$ by mass were produced These were assessed for gas sensitivity using the method described in the following section Sensors comprising polypyrrole alone and tin dioxide alone were also tested The results (displayed in Table 1) showed the composite containing $25 \% \mathrm{PPCl}$ by mass to give the greatest sensitivity and this was considered to be the optımum polymer weightıng Composite sensors containıng $25 \%$ polymer by mass were then produced using the other polymer derivatives Each polymer $(0025 \mathrm{~g})$ was added to tin dioxide $(00975 \mathrm{~g})$ and ground in water $(2 \mathrm{ml})$ to produce a coherent paste A known volume was then deposited across the interdigitated gold electrode and dried for $15 \mathrm{~min}$ at $60^{\circ} \mathrm{C}$ All sensors were then left for $48 \mathrm{~h}$ in clean air to equilibrate Duplicate sensors of each type were produced from batch 1 polymers (A and B sensors) and tested under identical conditions in order to assess consistency within a batch Similarly, composite sensors comprising batch 2 polymers were produced to assess the reproducibility of fabrication For comparison, batches of sensors comprising $\mathrm{PPCl}$ and tin dioxide alone were produced and tested All sensors were tested for their electrical responses to duplicate vapour injections of three differing concentrations $(1,10,100 \mathrm{ppm})$ of the test analytes methanol, ethanol, ethyl acetate, methyl acetate and acetone All sensors were tested for their response to the organic vapours at two different temperatures 20 and $40^{\circ} \mathrm{C}$ The results are displayed in Table 2 All sensors were retained and retested after six weeks to assess any ageing affects

\section{Sensor testing apparatus}

The sensors were tested in an in-house designed test chamber This consisted of a multi-port spherical glass vessel (total volume, $3375 \mathrm{dm}^{3}$ ) maintained in a heated (variable up to $c a$ $40^{\circ} \mathrm{C}$ ) chamber Three ports possessed electrical feed-throughs, two for connection to the sensors and one for connection to a semiconductor temperature sensor Two ports (one inlet, one outlet) were connected via electrically operated valves to provide a purging air supply, where the source was a blended synthetic air cylınder (MG Gas Products Ltd, Reigate, UK) One port contained a silicone rubber septum through which test vapours could be injected via a gas-tight syringe The sensors were connected through a Keithley 705 scanner to a Keithley 617 electrometer (Keithley Instruments Ltd, Readıng, UK) Both Kerthley instruments were connected via an IEEE488 interface to an IBM-compatible computer The software to gather and display the data was written in-house The voltage applied across the electrodes was $10 \mathrm{~V}$, supplied 
Table 2 Percentage change in current (applied voltage $1.0 \mathrm{~V}$ ), upon exposure to organic vapours, of tin dioxide, $\mathrm{PPCl}, \mathrm{PPCl}$ composite ${ }_{7} \mathrm{PP} \mathrm{P}_{\mathrm{N}} \mathrm{O}_{3}$ composite, PNMPCl composite and PNMPNO ${ }_{3}$ composite at 20 and $40^{\circ} \mathrm{C}$

\begin{tabular}{|c|c|c|c|c|c|c|c|c|}
\hline \multirow[b]{2}{*}{ test vapour } & \multirow[b]{2}{*}{ conc. (ppm) } & \multirow[b]{2}{*}{$T /{ }^{\circ} \mathrm{C}$} & \multicolumn{6}{|c|}{$\%$ change in current } \\
\hline & & & $\mathrm{SnO}_{2}$ & $\mathrm{PPCl}$ & $\begin{array}{c}\mathrm{PPCl} \\
\text { composite }\end{array}$ & $\begin{array}{c}\mathrm{PPNO}_{3} \\
\text { composite }\end{array}$ & $\begin{array}{l}\text { PNMPCl } \\
\text { composite }\end{array}$ & $\begin{array}{l}\mathrm{PNMPNO}_{3} \\
\text { composite }\end{array}$ \\
\hline \multirow[t]{6}{*}{ ethanol } & 1 & 20 & 9.8 & -2.5 & 21.7 & 9.8 & 11.3 & 9.5 \\
\hline & 1 & 40 & 12.6 & -2.1 & 30.7 & 15.1 & 17.1 & 16.3 \\
\hline & 10 & 20 & 15.3 & -4.4 & 32.3 & 17.6 & 22.1 & 20.1 \\
\hline & 10 & 40 & 20.7 & -4.1 & 65.4 & 26.1 & 27.2 & 24.1 \\
\hline & 100 & 20 & 30.7 & -6.1 & 76.4 & 34.6 & 33.7 & 37.9 \\
\hline & 100 & 40 & 41.2 & -5.7 & 103.1 & 37.2 & 45.5 & 38.9 \\
\hline \multirow{6}{*}{ methanol } & 1 & 20 & 8.1 & -2.1 & 11.3 & 4.6 & 7.2 & 8.1 \\
\hline & 1 & 40 & 9.5 & -2.2 & 18.5 & 9.1 & 9.5 & 10.1 \\
\hline & 10 & 20 & 13.2 & -2.4 & 21.7 & 9.3 & 14.1 & 13.4 \\
\hline & 10 & 40 & 14.3 & -2.1 & 32.5 & 15.3 & 16.1 & 15.2 \\
\hline & 100 & 20 & 17.8 & -3.6 & 41.9 & 16.5 & 23.4 & 20.6 \\
\hline & 100 & 40 & 21.3 & -2.9 & 49.9 & 21.2 & 21.6 & 21.3 \\
\hline \multirow[t]{6}{*}{ ethyl acetate } & 1 & 20 & 6.1 & -1.6 & 10.2 & 5.7 & 7.1 & 6.1 \\
\hline & 1 & 40 & 7.3 & -1.7 & 11.1 & 6.2 & 9.1 & 8.3 \\
\hline & 10 & 20 & 11.5 & -2 & 17.1 & 11.4 & 11.6 & 11.1 \\
\hline & 10 & 40 & 12.6 & -1.9 & 20.2 & 10.1 & 14.6 & 14.3 \\
\hline & 100 & 20 & 14.2 & -2.6 & 32.3 & 20.3 & 21.4 & 21.7 \\
\hline & 100 & 40 & 14.9 & -2.2 & 29.7 & 17.8 & 22.3 & 22.6 \\
\hline \multirow{6}{*}{ methyl acetate } & 1 & 20 & 5.7 & -1.4 & 9.1 & 5.2 & 6.3 & 6.5 \\
\hline & 1 & 40 & 6.4 & -1.6 & 15.1 & 7.2 & 10.1 & 9.1 \\
\hline & 10 & 20 & 10.1 & -2.1 & 18.3 & 9.1 & 11.2 & 12.3 \\
\hline & 10 & 40 & 11.3 & -2.3 & 26.6 & 11.3 & 15.3 & 14.6 \\
\hline & 100 & 20 & 15.1 & -2.8 & 26.1 & 15.2 & 16.3 & 18.1 \\
\hline & 100 & 40 & 16.4 & -2.7 & 36.1 & 16.8 & 20.8 & 21.3 \\
\hline \multirow[t]{6}{*}{ acetone } & 1 & 20 & 8.1 & -2.1 & 14.2 & 7.1 & 8.3 & 8.3 \\
\hline & 1 & 40 & 7.9 & -2.2 & 16.7 & 9.2 & 10.3 & 10.1 \\
\hline & 10 & 20 & 13.4 & -2.8 & 23.6 & 11.1 & 11.5 & 13.2 \\
\hline & 10 & 40 & 14.1 & -2.6 & 27.3 & 12.1 & 15.3 & 15.7 \\
\hline & 100 & 20 & 20.7 & -4.6 & 35.7 & 18.2 & 19.1 & 21.4 \\
\hline & 100 & 40 & 20.4 & -3.3 & 35.3 & 16.9 & 20.3 & 21.3 \\
\hline
\end{tabular}

from a programmable voltage source built into the Keithley 617 electrometer. All sensitivity results were measured in terms of percentage change in current.

\section{Results and Discussion}

Comparison of $\mathrm{C}: \mathrm{N}, \mathrm{N}: \mathrm{H}, \mathrm{C}: \mathrm{H}$ and $\mathrm{Cl}: \mathrm{N} / \mathrm{C}: \mathrm{Cl}$ (where applicable) ratios, ascertained from elemental analysis results performed on batch 1 and batch 2 polymers, showed that the reproducibility of synthesis was within $2 \%$ for each polymer type. The percentage yields of polymers were relatively low owing to the short reaction times used. Better yields might have been obtained if the reaction had been left for $24 \mathrm{~h}$, although this could have resulted in over-oxidation of the polymer. Losses can also be explained by the formation of soluble oligomers which would have been removed during the work-up.

The optimum polymer weighting was found to be $2.5 \%$ by mass for the composite sensors incorporating PPCl. The effect on the response to $100 \mathrm{ppm}$ of ethanol vapour of varying the mix ratio is shown in Table 1, where the results are quoted relative to the response of the most sensitive composite. On testing with the other vapours of interest, the $2.5 \% \mathrm{mix}$ ratio also gave the highest sensitivity. The composite sensors, where the polymer is present at a low level, exhibited a resistance decrease implying overall n-type conduction, as was observed for tin dioxide alone. The negative results indicate a resistance increase upon exposure to the vapours, implying a reversion from n-type to p-type conduction. This was observed for composites which contained more than $50 \%$ polypyrrole by mass. These results suggest that two competitive mechanisms occur within the composite sensors.

Sensitivity results displayed in Table 2 were all calculated using the following relationship: $100\left(I_{\mathrm{g}}-I_{\mathrm{o}}\right) / I_{\mathrm{o}}$, where $I_{\mathrm{g}}$ is the current two minutes after the injection of the test vapour, and $I_{\mathrm{o}}$ is the stable baseline current prior to injection. The results show that at room temperature the composite sensors generally gave enhanced responses to the organic vapours when compared with the responses of sensors constructed of tin dioxide or polymer alone.

As discussed earlier, the electronic properties of the composites appear to be governed by tin dioxide, and therefore when exposed to electron-donating vapours or gases they exhibit a decrease in resistance, whereas sensors composed solely of polypyrrole exhibit an increase in resistance. It is postulated that the observed increased sensitivity for composite materials may be due to the creation of a positively charged depletion layer on the surface of the tin dioxide which could be formed owing to inter-particle electron migration from tin dioxide to polypyrrole at the heterojunctions. This would cause a lowering of the activation energy and enthalpy of physisorption for vapours with good electron-donating characteristics, whilst still permitting reversibility.

The results in Table 2 show little correlation between gas sensitivity and temperature for the composite sensors. Although slight enhancements in sensitivity are observed with some composite sensors, the difference is not considered great enough to warrant external heating of the sensors in a practical device.

The results displayed in Table 2 are for group A sensors made up with batch 1 polymers. Testing of group B sensors and sensors made up with batch 2 polymers elucidated similar response profiles with similar sensitivity values obtained (within $10 \%$ ). Therefore sensors which are reproducible in terms of sensitivity both intra- and inter-batch can be produced. Variations in the initial baseline current of up to $40 \%$ may occur between sensors of the same type. The composite sensors tended to drift towards lower resistance, with a figure of $5 \%$ per hour typical when under test. A number of solutions to improve the reproducibility of fabrication are currently under investigation, such as screen printing or pre-coating of the tin dioxide particles with polymer prior to sensor production. 
The reproducibility of response for the sensors containing only tin dioxide was poor, typically $30 \%$ difference between batches The baselines of these tin dioxide sensors tended to drift towards lower resistance (up to $15 \%$ per hour when under test) resultıng in poor response data The sensors containing only polypyrrole derivatives gave highly reproducible responses, typically withın $5 \%$ The baseline stability was high with no appreciable drift during a week of testing These sensors gave very low sensitivities when compared to the tin dioxide or the composite sensors

A typical run profile carried out in dry air (Fig 2$)$ is included which shows the response of the $\mathrm{PPCl}$ composite sensor to three consecutive vapour injections of ethanol in the range $10-1000 \mathrm{ppm}$ The responses reached $90 \%$ of the maximum within $3 \mathrm{~min}$ and were $90 \%$ reversible within $5 \mathrm{~min}$ for the case of a $500 \mathrm{ppm}$ injection of ethanol It should be noted that the adsorption kinetics of composite sensors at lower concentrations such as $10 \mathrm{ppm}$ are slower, with $90 \%$ of the maximum response reached within 4 min The adsorption and desorption kinetics of the polymer are marginally faster than those of the composites with $90 \%$ of the maximum response reached within $2 \mathrm{~min}$ and $90 \%$ recovery within $3 \mathrm{~min}$ Sensors constructed from tin dioxide alone exhibit similar adsorption kinetics to those of the composite sensors However, the desorption kınetics are slow with only $50 \%$ recovery after 5 min For all composite sensors and individual component sensors the adsorption kinetics were found to be dependent on analyte concentration, but independent of analyte type (for the vapours tested) In contrast, the desorption kinetics of the sensors were found to be independent of analyte concentration, but dependent upon analyte type The desorption kinetics were slower when the sensors had been exposed to the esters For example, a $\mathrm{PPCl}$ composite was $90 \%$ reversible after $6 \mathrm{~min}$ when exposed to a 500 ppm injection of ethyl acetate $F_{1 g} 3$ displays current vs time data for the $\mathrm{PPCl}$ composite when exposed to $500 \mathrm{ppm}$ ethanol

Fig 4 shows that saturation of composite and individual

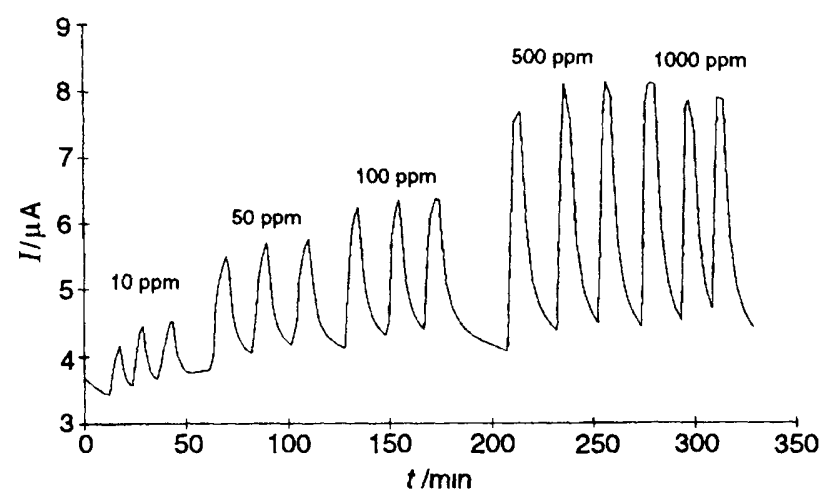

Fig. 2 Change in current of a PPCl-tin dioxide composite upon exposure to ethanol vapour in the range $10-1000 \mathrm{ppm}(10 \mathrm{~V}$ applied $)$

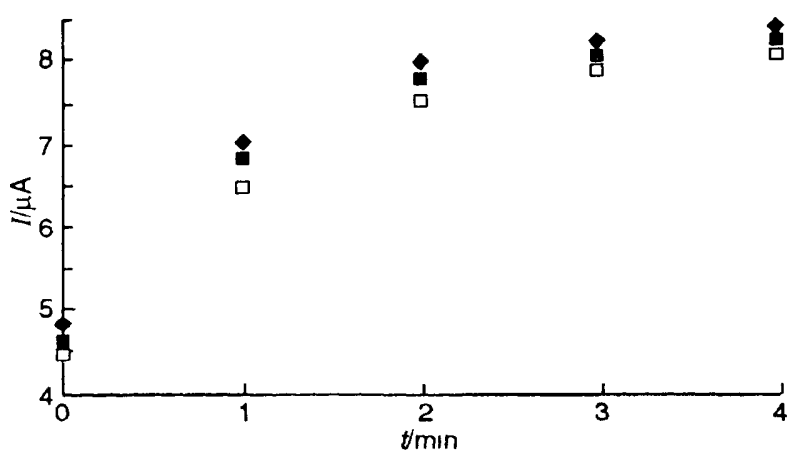

Fig. 3 Current $v$ s time data for the $\mathrm{PPCl}$ composite when exposed to three 500 ppm injections $(\square, \boldsymbol{\square}, \bullet)$ of ethanol vapour

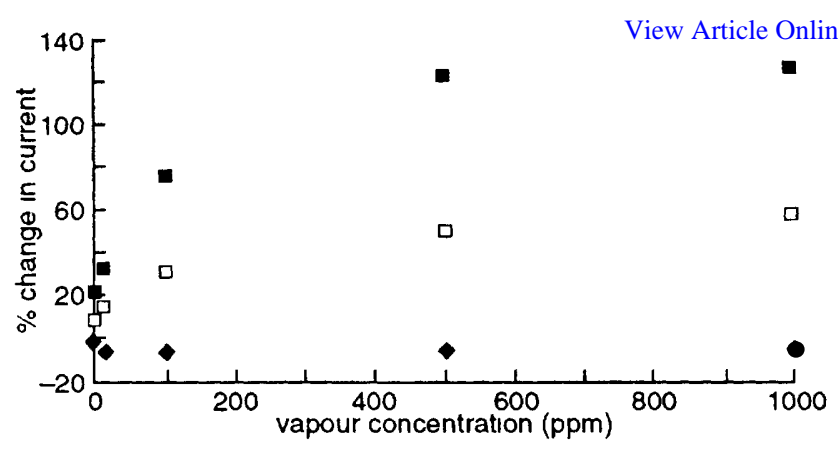

Fig. 4 Percentage change in current vs ethanol concentration for the $\mathrm{PPCl}$ composite $(\square)$, tin dioxide $(\square)$ and $\mathrm{PPCl}(\bullet)$ sensors

component sensors occurred at ethanol vapour concentrations $>500 \mathrm{ppm}$ The saturation effect at this level is evident for all the analytes tested, and this is shown in Fig 5

Baseline stability studies under ambient conditions over two weeks showed that after an initial settling period of four days the composite sensors exhibited good stability with fluctuations in the initial resistance of $<7 \%$ per week This compares favourably with literature values reported for an electropolymerised polymer film of a $10 \%$ change in baselıne resistance over two weeks ${ }^{19}$ As reported, the fluctuation was greater when the sensors were tested contınuously However, when testing was complete, the composite sensors returned to within $2 \%$ of their original baseline value The baseline stability of the tin dioxide sensors is poor, with fluctuations of $20 \%$ per week under ambient conditions In contrast, the baseline fluctuations of the polymer sensors were typically less than $5 \%$ per week

Studies of the responses of the sensors to different relative humidities over the range 20-98\% (F1g 6-9) showed that the composite sensors, as well as polypyrrole and tin dioxide alone, were humidity dependent Composites incorporating poly- $N$ methyl pyrroles were found to be particularly sensitive to

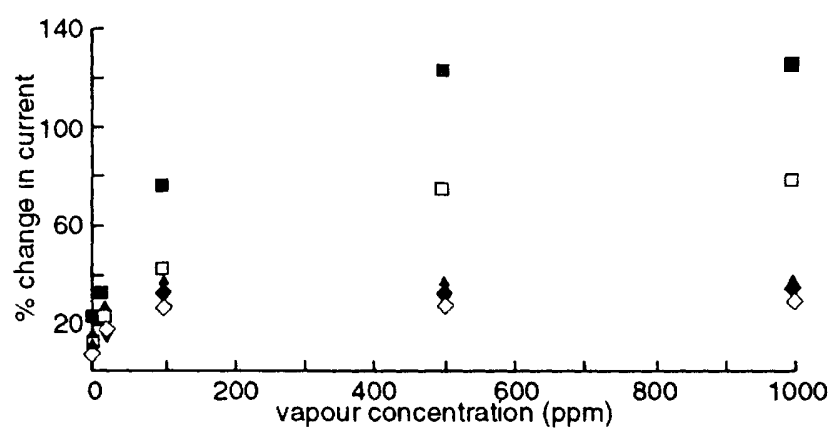

Fig. 5 Percentage change in current of the $\mathrm{PPCl}$ composite sensor vs analyte concentration $\square$, ethanol, $\square$, methanol, $\bullet$, ethylacetate, $\diamond$, methyl acetate, $\boldsymbol{\Lambda}$, acetone

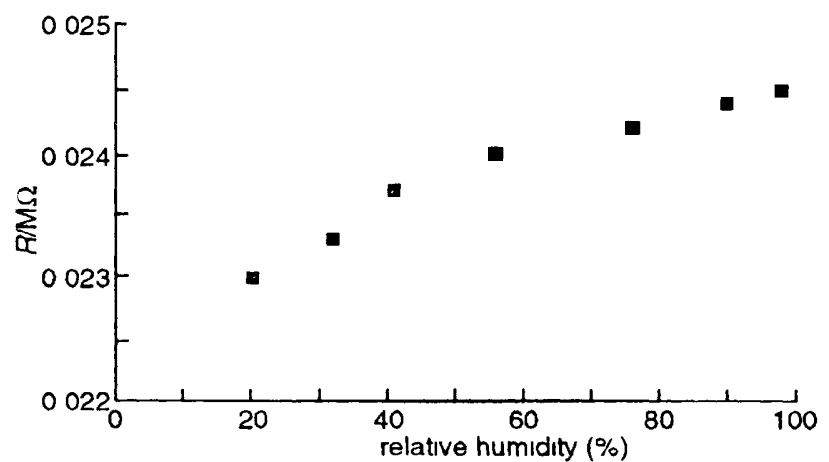

Fig. 6 Resistance change for the $\mathrm{PPCl}$ sensor on exposure to a range of relative humidities 


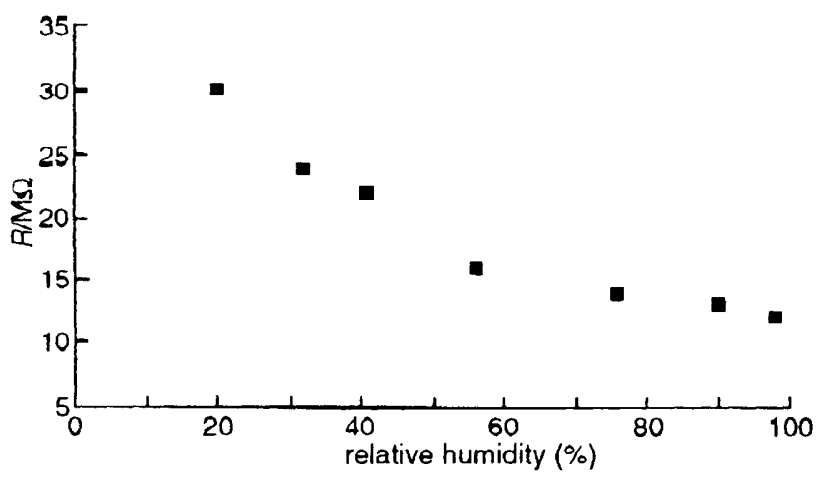

Fig. 7 Resistance change for the tin dioxide sensor on exposure to a range of relative humidities

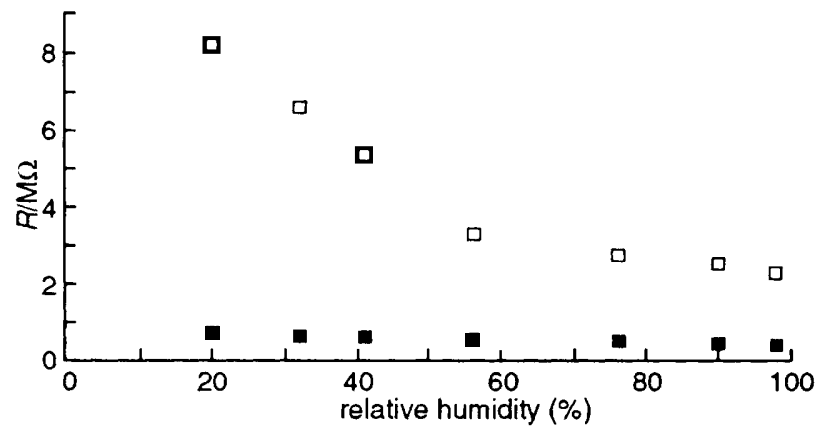

Fig. 8 Resistance change for the $\mathrm{PPCl}(\boldsymbol{\square})$ and $\mathrm{PPNO}_{3}(\square)$ composite sensors on exposure to a range of relative humidities

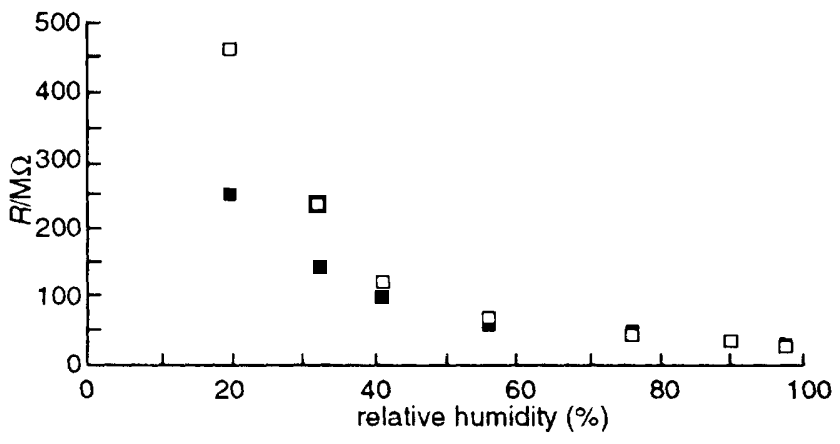

Fig. 9 Resistance change for the PNMPCl (ם) and $\mathrm{PNMPNO}_{3}(\square)$ composite sensors on exposure to a range of relative humidities

humidity changes. Composites incorporating $\mathrm{PPCl}$ were relatively unaffected by humidity changes, whilst being most sensitive to organic vapours. These observations may be partly explained by the differential interaction of water vapour with the solvation sheaths surrounding the dopant anions of the polymers. However, the results show the polymer type to be the major contributing factor to the humidity dependence. Distinct response patterns to humidity were observed, which would permit simple compensation in a practical device, assuming baseline drift can be reduced.

Testing of the composites and individual components towards ethanol $(500 \mathrm{ppm})$ under $50 \%$ humidity conditions gave sensitivity values typically $65 \%$ of those obtained in dry conditions, suggesting that competitive rather than additive effects are observed with humidity. Under ambient humidity conditions all composite sensors exhibited slower adsorption and desorption kinetics. The composite sensors reached $90 \%$ of the maximum response within $4 \mathrm{~min}$ and were $90 \%$ reversible within $6 \mathrm{~min}$. Sensors constructed solely of tin dioxide gave sensitivity values typically $50 \%$ of those observed when tested under dry conditions. Adsorption kinetics were similar to the composites, but desorption kinetics were slower with sensors only $50 \%$ reversible within $8 \mathrm{~min}$. Sensors constructed solely of polypyrrole derivatives gave sensitivity values typically $75 \%$ of those observed when tested under dry conditions. Adsorption and desorption kinetics were $50 \%$ slower than when tested under dry conditions.

All sensors were retested after six weeks and the results showed that despite a small decrease in sensitivity (typically $5-10 \%)$, the response profiles and baseline stabilities were similar. The behaviour of the PPCl sensors was erratic with a substantial loss of gas sensitivity in some sensors. This can be explained by the low mechanical strength of sensors based on chemically prepared polypyrroles which are highly intractable materials. The sensors based on tin dioxide alone had drifted to much lower resistances over this time, but still gave sensitivity values comparable to those obtained when they were first tested (within $20 \%$ of the original values).

Gas sensitivity was found to be dependent upon the polymer derivative, the associated anion, and the synthesis conditions of the polymers incorporated in the composites. This is in agreement with literature data $\mathrm{a}^{20,21}$ on the responses of pyrrolebased systems for gas sensing.

The sensitivity of the composite sensors compares favourably at lower vapour concentrations with heated thin-film systems cited in the literature, ${ }^{3}$ whilst power consumption is minimal in comparison. Comparison with reported ${ }^{22}$ sensitivities of electropolymerised polymers to organic vapours at room temperature shows composite sensors generally to be more sensitive, especially to alcohols. Sensitivities of $0.5 \%$ are quoted on exposure to $1600 \mathrm{ppm}$ of methanol vapour for a single polymer incorporated in an array-type device. ${ }^{22}$ Quoted linear sensitivity ranges for both thin-film sensors and electropolymerised films are superior to composite sensors where saturation occurs above the $500 \mathrm{ppm}$ level. However, for applications in the early detection of soft rot in stored potato tubers the concentrations of interest will be in the low ppm range.

\section{Conclusion}

Novel vapour sensors for the detection of organic vapours have been fabricated from composites of polypyrrole derivatives and tin dioxide. The sensors, which operate at room temperature, respond reproducibly and reversibly to low concentrations of a range of organic species, such as esters, alcohols and ketones. Sensitivities at low concentrations compare favourably with common existing sensor types based on ceramic materials and electropolymerised polymer films. Importantly, some of the sensors tested possess different relative responses to the vapours, thus permitting their use as part of an array of sensors for vapour discrimination. All these factors suggest possible applications in the quality control of foodstuffs, specifically in the early detection of soft rot in potato tubers. Future work will be involved in optimising the fabrication conditions to improve the reproducibility of manufacture and addressing problems such as humidity dependence and baseline stability. Further optimisation must be carried out before the composites could be incorporated into a practical device for vapour sensing.

\section{References}

1 J. J. Miasik, A. Hooper and B. C. Tofield, J. Chem. Soc., Faraday Trans. 1, 1986, 82, 117.

2 T. C. Pearce, J. W. Gardner, S. Friel, P. N. Bartlett and N. Blair, Analyst, 1993, 118, 371.

3 Y. K. Fang and J. J. Lee, Thin Solid Films, 1989, 169, 51.

4 T. Maekawa, J. Tamaki, N. Miura and N. Yamazoe, Sensors Actuators, 1992, 9, 63.

$5 \mathrm{~J}$. Watson and $\mathrm{K}$. Ihokura, The Stannic Oxide Gas Sensor Principles and Applications, CRC Press, Boca Raton, FL, 1994.

6 W. E. Howard, J. Luminescence, 1981, 24/25, 835. 
7 I Rodriguez and J Gonzalez Velasco, J Mater Scı Lett, 1987, 6, 1319

8 S Maeda and S Armes, Chem Mater , 1995, 7, 171

9 J H Burroughes, D. D Bradley, A R Brown, R N Marks, K Mackay, R H Friend, P L Burns and A B Holmes Nature, 1990, 347539

10 A J Frank and K Honda, J Phys Chem, 1982, 86, 1933

11 T Woda, A Takeno, M Iwakı and H Sasabe, Synth Met 1987, 18,585

12 H Sasabe, T Furuno and T Wada, Mol Cryst Liq Cryst, 1988, 160, 281

13 J L Varns and M T Glynn, Am Pot Jn, 1979, 56, 185

14 J W Gardner, E L Hines and H C Tang, Sensors Actuators B, $1992,9,9$

15 K Persaud and G Dodd, Nature, 1982, 299, 352

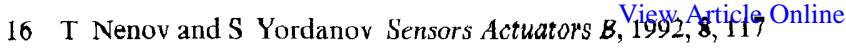

17 J V Hatfield, P J Hicks P Neaves, K C Persaud and P Travers, Sensors (VI) Technology Systems and Applications, ed K T V Grattan and A T Augostıni, Institute of Physics, Bristol, 1993

18 R E Myers, $J$ Electron Mater 1986, 15, 61

19 H V Shurmer, P Corcoran and J W Gardner, Sensors Actuators $B, 1991,4,29$

20 T Hanawa, S Kuwabata and H Yoneyama, J Chem Soc, Faraday Trans 1, 1988, 84, 1587

21 J M Slater and E J Watt, Analyst, 1992, 117, 1265

$22 \mathrm{~J}$ V Hatfield, P Neaves, P J Hicks, K Persaud and P Travers, Sensors Actuators B, 1994, 18-19, 221

Paper 5/04829J, Received 21st July, 1995 